\title{
Sustainable urbanization in the context of environmental chemistry and life cycle issues
}

\author{
P. Peltonen \& H. Mälkki \\ Helsinki University of Technology (Aalto University) TKK Lahti Center, \\ Finland
}

\begin{abstract}
The article approaches present phenomena in urbanization, such as population increase, urban sprawl, heat island and dust dome trap problems. Environmental impacts such as climate change, acidification, toxic substances and wastes are evaluated. After a background survey, the article proceeds to the chemistry of the urban environment, and focuses on recent phenomena in ozone formation. European inventories in environmental city chemistry are surveyed. One problem is the bad ozone ground-layer troposphere. Particulate matter concerns exposure of urban population. Acidifying pollutants and other air pollutants such as lead, benzene, cadmium and mercury in urban air are evaluated. The objective is to find remarks which could be exploited when planning overall urban wellbeing for the future. To this belongs obligations, standards, other guidance, sustainability of urban housing, health questions and education. The aim is to find updated tools for urban environmental management in urban rivers, sewage waters, wastes and recycling with their life cycle issues together with their consumption.
\end{abstract}

Keywords: urbanization, emissions, environmental impacts, chemical and metal pollutants, guidance, life-cycle issues.

\section{Introduction}

For the first time in human history, more people are living in towns and cities than in rural areas. Europe is one of the most urbanized continents. Approximately $75 \%$ of its population live in urban areas; by 2020 , this will be $80 \%$. As a result, the demand for land in and around cities is becoming acute; urban sprawl is re-shaping landscapes and affecting people's quality of life and 
the environment as never before. Urban planning and management have risen high on the political agenda, with transport and housing as crucial challenges, see The European Environment Agency (EEA) [1].

The growth of cities in Europe has historically been driven by increasing urban populations. However, today, even where there is little or no population pressure, a variety of factors are still driving urban sprawl. These are rooted in the desire to realize new lifestyles in suburban environments outside the inner city. The mixture of forces behind these trends include both micro and macro socioeconomic trends, which are resulting in sprawling cities all over Europe. The areas with the most visible impacts of urban sprawl are in countries or regions with a high population density and economic growth. Sprawl is particularly evident where regions have benefited from EU policies and funding which better reflect a vision of urban development. Urban waste and waste-water treatment enjoy economies of the more concentrated population scale. Traditional environmental health problems from unsafe drinking water, inadequate sanitation and poor housing have largely disappeared from cities within the EU, EEA [2]).

Urban sprawl means in modern cities a phenomenon where urban housing with transportation is spread by increasing, largely, the in-and-out traffic of the city. This can be typical, e.g. to the multiple-nuclei urban spatial model of a city structure where a lot of people are driving daily from the residential areas to the central business area of a city, Fig. 1 by Tyler Miller [3].

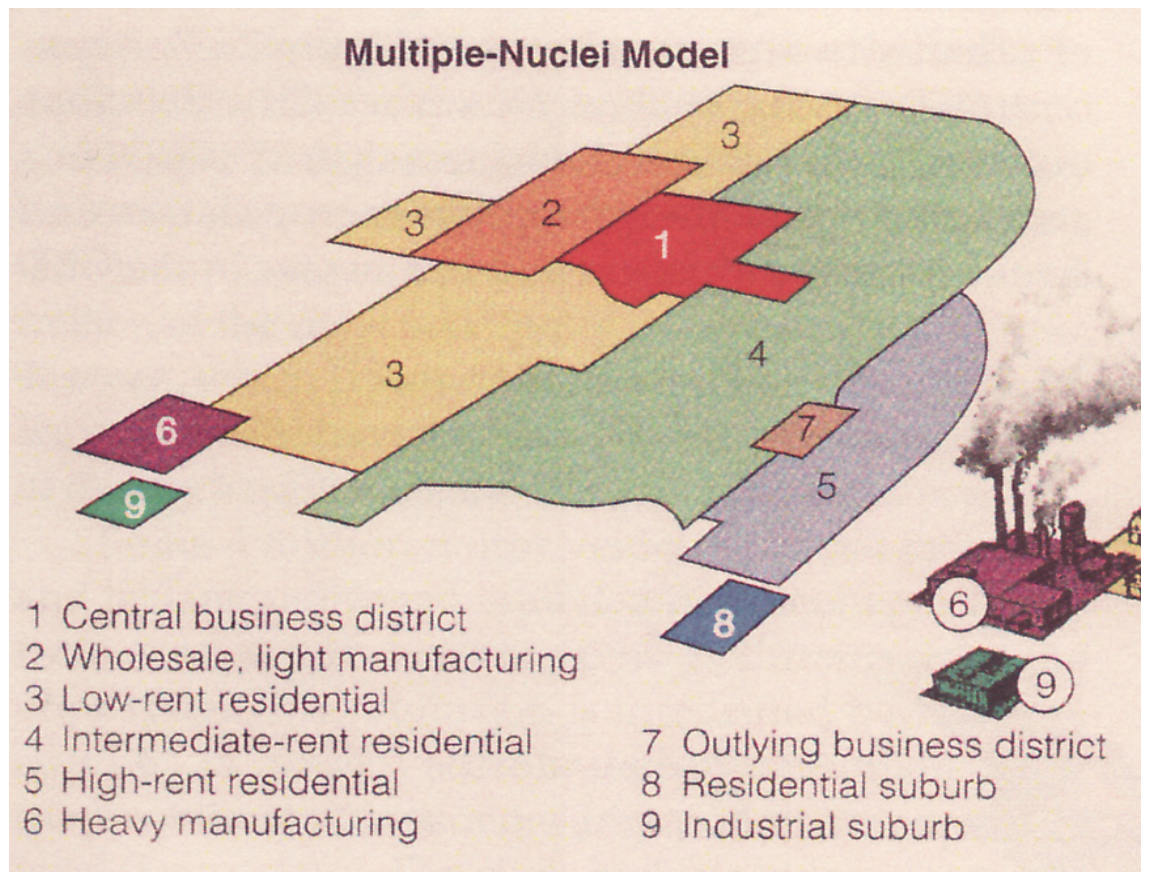

Figure 1: $\quad$ One of the spatial structures of an urban area is a multiple-nuclei model. 
Simple models can be used to identify general patterns of urban development although no city perfectly matches any of them (Tyler Miller [3]). The urban heat island effect is also explained by Tyler Miller to be a phenomenon where an urban heat island causes patterns of air circulation that create a dust dome over the city. Winds can elongate the dome movement towards the downwind areas. A strong cold front can blow the dome away. This lowers the local pollution level in particulates of inhaled air in the city but increases, however, the dust dome effect in the downwind areas. Those most harmful particles are less than $10 \mu \mathrm{m}$ in diameter - hence the term PM10. Studies in the USA, and monitoring in EU, show that the death rates in respiratory diseases have increased when concentrations of PM10 have increased [4].

The National Emission Ceilings Directive (NECD) [5] requires now all 27 Member States of the EU to report information annually concerning emissions for four main air pollutants: sulphur dioxide $\left(\mathrm{SO}_{2}\right)$, nitrogen oxides $\left(\mathrm{NO}_{\mathrm{X}}\right)$, nonmethane volatile organic compounds (NMVOCs), and ammonia $\left(\mathrm{NH}_{3}\right)$. These pollutants harm human health and the environment by causing ozone, particulate matter, acidification and eutrophication formation. The NECD will set legally binding emission ceilings for these pollutants which must be met by 2010 [5].

\section{Urban environmental impacts}

Pollution in urban environment occurs often due to human activity. That causes element, chemical or substance level that can disrupt or to be toxic to human health. This is often a driving force behind the clean-up procedures. An example is the release of sulphur dioxide due to the burning of fossil fuels. Coal burning and smoke emissions have a link to the respiratory diseases and asthma, and the same emissions of power stations, a link to formation of acid rain. Major sources of pollutants and their effects presented by Pulford and Flowers [6] can be listed as follows:

Industry

- release of heavy metals - toxicities

- release of organics - toxicities

- smoke and gas emissions - health effects

Power production

- $\mathrm{SO}_{2}$ emissions - acidification - health effects

- $\mathrm{CO}_{2}$ emissions - greenhouse gas

Mining

- Acid mine drainage $\left(\mathrm{SO}_{2}\right)$ - acidification, health effects

- release of heavy metals - toxicities

Transport

- $\mathrm{NO}_{\mathrm{X}}, \mathrm{CO}_{2}$ emissions - greenhouse gas, ozone

- $\mathrm{Pb}$ emissions - health effects

- Particulates matter - health effects

Domestics

- Organic wastes to landfills - leachate and methane

- Sewage disposal - heavy metals and organics (chemicals) 
Agriculture

- Nutrient leaching and enrichment - eutrophication and surface waters

- $\mathrm{NO}_{2}, \mathrm{NH}_{3}$ (ammonia), methane emissions - eutrophication, greenhouse gas

- Slurry effluents, fertilizers - contamination of lakes and rivers

The climate of cities often differs from that experienced in the surrounding rural and agricultural areas (Fig. 1). The above mentioned industrial, power plant and domestic pollution has influence on city air although the most typical pollution source is transportation and traffic. In cities, the narrow streets and high and crowded buildings, like in New York, can become hot in summer. Urbanization alters the nature of the local atmosphere of these streets. Other aspects of climate in cities which can alter the radiation-heat balance are wind speed, humidity and precipitation. For example, although urbanization frequently reduces average wind speed, the positioning of buildings can create long, narrow streets producing an unpleasant wind tunnel effect on occasion, resulting in very strong gusts of winds. Similarly, the urban heat island effect will rarely, if ever, be uniform across a city, due to the uneven distribution of dense building materials which can store heat for subsequent release, and heavily trafficked streets where vehicle engines release heat [7].

Shopping centres, central business districts and areas of high-density housing in cities (Fig. 1) often have more elevated air temperatures than parks or lowdensity housing areas. Uncomfortable high air temperatures during summer in big cities can contribute to higher-than-average death rates among older people. Urban heat island effect arises thus from the burning of fossil fuels in power generation, space heating and transportation and the lower average wind speed reduces the potentiality for heat to move away from urban areas [7]. When a city area is warmer, rainier, foggier and cloudier together with the enormous heat amounts generated by cars, factories, lights and conditioners, the especially difficult urban heat island phenomenon can exist over the city atmosphere [3].

\subsection{Ozone formation}

Ground-level ozone is among the most harmful air pollutants in cities. 10 to $50 \mathrm{~km}$ above the Earth's surface, ozone is good as it protects life on Earth from the sun's ultraviolet rays. Remember, however, that the sc. ozone hole phenomenon is again caused by the CFCs (Freon gases) and is an influence which causes climate change. In the troposphere up to $1-15 \mathrm{~km}$ from the Earth's surface (and in cities), car engines' $\mathrm{NO}_{\mathrm{x}}$ (also the combustion of fossil fuels, $\mathrm{CO}$, VOCs emissions) increases in sunlight the amount of the sc. bad ground-level ozone. These elevated levels of ozone can exist over the city sky and can cause health problems, even deaths, together with the high air humidity. Ground-level ozone has become not only an urban but even a global air and climate change problem. Many atmospheric chemists and researchers are now trying to solve the ground-level ozone problems [8]. 
The majority from the bad tropospheric ozone formation occurs when nitrogen oxide (NOx, engine/traffic origin), carbon monoxide (CO) and volatile organic hydrocarbons (VOCs), such as xylene, react in the atmosphere in the presence of sunlight, on UV-light rays, wave length 280-320 nm. Precursors of ozone originate from urban areas (NOx from engines) but winds can carry precursors of ozone for hundreds of kilometers. To oxidants which can have effect on ozone formation are classified chemicals such as peroxyacetyl nitrates (PANs), formaldehyde, acetaldehyde, hydrogen peroxide and hydroxy radicals. To VOCs are classified, e.g. hydrocarbons like methane, butane, ethylene, benzene, benzopyrene, formaldehyde, chloroform and methylene chloride [7-9].

\subsection{Acid deposition}

To acid deposition of city environment influences sulphur dioxide $\left(\mathrm{SO}_{2}\right)$, nitrogen oxides $\left(\mathrm{NO}_{\mathrm{x}}\right)$ and ammonia $\left(\mathrm{NH}_{3}\right)$. Sulphur oxides can contribute acid deposition to aquatic ecosystems. Sulphates can reduce visibility even at low concentrations. Nitrogen oxides can damage aquatic ecosystems, forests and cause climate change [7]. Nitrogen monoxide (NO) and nitrogen oxide, in the photochemical smog formation process, contribute ozone formation and indirectly increase infections, lung diseases, and eye, nose and throat irritation [7]. The acidifying emission measurements of $\mathrm{NO}_{\mathrm{X}}, \mathrm{SO}_{2}, \mathrm{NH}_{3}$ concentrations in EU-27 Member States, compared to the NEC Directive ceiling values between 1990-2010, have notably decreased and have a lowering tendency. The values in 2010 were almost at limits of NECD although they still must be lowered [10].

\subsection{Toxic hydrocarbons}

Hydrocarbon is a general term used for several organic compounds emitted when petroleum fuels are burned. Automobile exhaust accounts for over half of the complex mixture of hydrocarbons emitted to the atmosphere in urban areas. Usually hydrocarbons consist of methane, ethane, propane, and derivatives of aliphatic and aromatic organic compounds. The combustion of fuels, the gasoline and diesel engines in traffic and in maintenance, transportation, construction and industry can cause hydrocarbon emissions. Hydrocarbons are of concern primarily for their role in the formation of photochemical oxidants and smog (ozone problem). The bad health effects in the inhalation of air occur only at high concentrations of the hydrocarbon emissions. Low concentrations can, however, cause headaches, breathing problems and eye irritation (Jain et al. [11]).

Most hazardous to human health are such organic compounds which are very volatile in their structure and which are easily evaporated at normal temperatures. To these hydrocarbons belong chemicals like benzene, bentzo(a)pyrene (PAH), carbontetrachloride and formaldehyde. Benzene can originate from petrol-fuelled internal combustion engines; bentzo(a)pyrene from the by-product of incomplete combustion of diesel fuel; carbontetrachloride from cleaning agents for machinery and formaldehyde from petroleum refining and from the combustion exhaust of engines. All the above mentioned chemicals are toxic and carcinogenic and their usage is broadly inhibited by the present EU 
chemical regulation $(\mathrm{REACH})$ and the other directives (Jain et al. [11]). EEA annual average measurements in EU-25 countries, calculations in 2004, showed that very toxic benzene can, even still, in few measurements, exist in urban and street conditions over the average limit value shown by EEA calculations [12].

Benzene as an aromatic hydrocarbon has, for long been well-known as a carcinogenic chemical, especially by its leukemic cancer risk (Aksoy [13] and OECD (1985a) [14]). For example in a study of the organic fraction of airborne particulates, in among others, in Athens in 1990, there was shown that the organic extracts of airborne particulate matter showed direct mutagenic activity which was correlated with benzo(a)pyrene chemical in the air. This chemical is one from the sc. very carcinogenic polycyclic aromatic hydrocarbon group of PAHs. In addition, the concentration of PAHs was greatest for particles with a diameter less than $3.3 \mu \mathrm{m}$. the effects of the particulate matters are researched, among others, by Jain et al. [11] and Van Houdt [15].

\subsection{Heavy metals}

Some toxic metals, their emissions and major health effects in city air are known. These metals are Cadmium (Cd) in combustion of fossil fuels and in the burning of waste incineration, Lead $(\mathrm{Pb})$ in gasoline combustion and in legacy of petrol derived lead, Mercury $(\mathrm{Hg})$ in coal combustion and in fossil fuel burning, Arsenic (As) in coal burning and Nickel (Ni) in sewage sludge disposal. Cadmium is carcinogen, can cause damage to liver, kidneys, lungs and blood

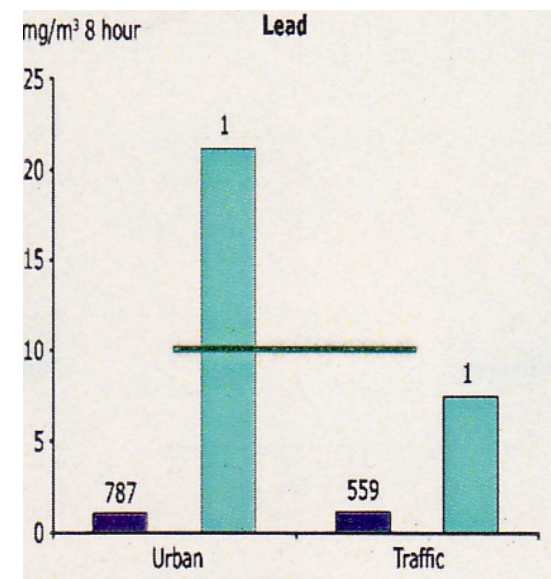

Average $\square$ Average > limit value

[ Maximum - Limit value

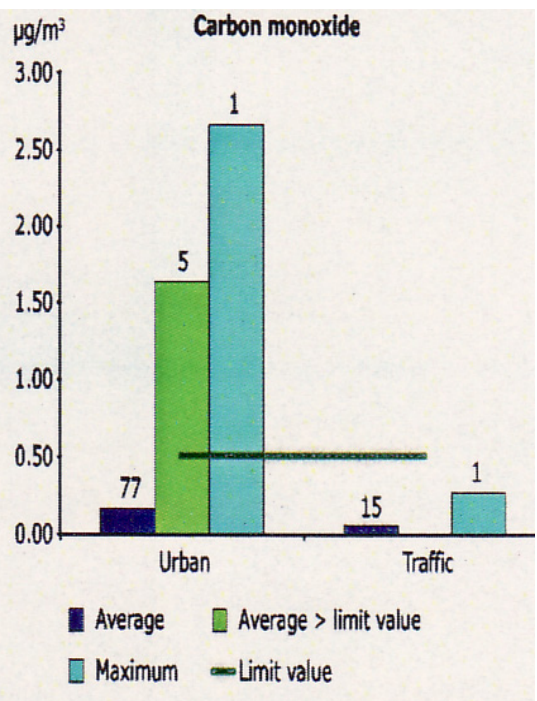

Figure 2: Lead and carbon monoxide (exhaust gas) average values in urban and in traffic areas. Left: average (787), maximum (1) and limit values only; right: average (77), average values over limit value (5) and maximum values (1). 
(anaemia). Lead is very toxic and can cause neurologic problems. Mercury can cause low-level chronic poisoning and headache. Arsenic and Nickel are both highly toxic carcinogens. All these metals can also have serious impacts on the aquatic environment. The main sources of metals in the environment are domestic and industrial waste-waters and the dumping of sewage sludge $[6,7]$.

In urban air circumstances the very low concentrations of metals, are, however, at levels of either mg (micro gram) or ng (nano gram) in cubic meter of air, been measured. There is not, however, existing any direct influence or hazard to human health from these very low concentrations of metals. EEA EU-25 countries are, however, measured in 2004, the main metal impurities' amounts. The average annual amount calculations are followed-up with Lead $(\mathrm{Pb})$, Arsenic (As), Cadmium (Cd) and Nickel (Ni) and with carbon monoxide (CO). Results of $\mathrm{Pb}$ and $\mathrm{CO}$ are in Fig. 2. Calculations are made during an $8 \mathrm{~h}$ exposure time [16].

Only a few measurements (Fig. 2) in urban air with $\mathrm{Pb}$ and $\mathrm{CO}$ have been over the limit value. In traffic it seems that we have not had any values over the limit which is a good development concerning health effects, EEA-25 [16]. In urban areas also As, Cd and Ni average value calculations by EEA-25 (2004) show that from the measurements only very few are over the maximum limit value. Cadmium $(\mathrm{Cd})$ is a very toxic metal. Cd values show still rather high variation in city air measurements which means that it is very important to continue the follow-up control by EEA. Based on larger results, it is better to also explain the variation with metals in EU city air; EEA-25 (2004) [17].

\section{Particulate matter, exposure and health}

Particulates are finely divided solid and liquid particles, suspended in the atmosphere. Commonly there are measured PM10 and PM2.5 microns in diameter sized particles. Particulates less than 10 microns can scatter light and behave as a gas. These particulates are also called aerosols. Those most dangerous to health are evaluated to be 2.5 microns (PM2.5) particulate matter. Air particulates determine air quality and very often urban exposure which can be dermal, oral or inhalation shown by Jain et al. [11]. Although air quality has improved in recent decades (and particularly in the large urban areas), nearly all urban citizens still experience an exceeding of EU urban air quality standards. In 1995 , in EU still about the following \%-amounts from the urban population were potentially exposed to too high amounts of air pollutants:

$\begin{array}{lll}\text { - } & \text { PM10 particulates } & 90 \% \text { (from potential population) } \\ \text { - } & \text { Nitrogen dioxide } & 65 \% \\ \text { - } & \text { Benzene } & 55 \% \\ \text { - } & \text { Ozone } & 50 \% \\ \text { - } & \text { Lead } & 20 \% \\ \text { - } & \text { Carbon monoxide } & 15 \%\end{array}$

In every case, these potential exposure amounts are still now too high, EU (1995) [18]. The highest exposure with about of $90 \%$ exists with potential population 
exposure on PM10 particulate matter. As potential exposure sources are also nitrogen oxide, even sometimes benzene and potential emissions of ozone. The calendar year, daily and $8 \mathrm{~h}$ limits for these pollutants are recently also published. For most polluting sources these limits are as follows: calendar year limit for nitrogen oxides in air is $40 \mu \mathrm{g} / \mathrm{c}$.a., for PM10 particulates $20-40 \mu \mathrm{g} / \mathrm{c}$.a., for benzene $5 \mu \mathrm{g} / \mathrm{m}^{3} / \mathrm{c}$.a. and for Lead $0.5 \mu \mathrm{g} / \mathrm{m}^{3} / \mathrm{c}$.a.. Limit for a short time carbon monoxide exposure in $8 \mathrm{~h}$ is $10 \mathrm{mg} / \mathrm{m}^{3}$ air and for ozone, the limit is for daily $8 \mathrm{~h}$ maximum which means that $120 \mu \mathrm{g} / \mathrm{m}^{3}$ ozone cannot be exceeded more than 20 days per calendar year $[18,19]$.

In the long-term exposure follow-up of the European air quality, the year 2003 has been the worst concerning just, e.g. the exposure of PM10 particulate matters, ozone and nitrogen dioxides. Just in 2003, about $60 \%$ from the population in cities was exposed to too high pollutant levels. This year 2003 (hot summer time) was also very difficult for people who can have health problems from polluted air. It seams that in big cities, we cannot either totally avoid this potential high exposure possibility to pollutants but we must, however, make now all possible efforts together, for the future, to be needed for lowering the exposure levels. The EEA has also published average measurements in PM10 concentrations in different EU cities. Some towns in the EU seem to be such where particulates can have been rather high existing amounts in recent years; especially in 2003 towns: Ostrava, Usti Nad Labem, Rotterdam and Prague had higher PM10 values. It is, however, very difficult to say the final explanation of these results because the variation in results is very high (EEA [20]).

\section{Life-cycle issues}

\subsection{Wastes and recycling}

The amount of municipal waste is expected to grow by $25 \%$ from 2005 to 2020 . The increased recovery of waste, and diverting waste away from landfill, play a key role in tackling the environmental impacts of increasing waste volumes. As recycling and incineration with energy recovery are increasingly used, net greenhouse gas emissions from municipal waste management are expected to drop considerably by 2020 . Limiting or avoiding growth in waste volumes would further reduce greenhouse gas emissions from the waste sector and deliver other benefits to society and the environment [21]. Recycling and other materialrecovery operations are expected to increase from the current level of $36 \%$ to around $42 \%$ by 2020 . Net emissions of greenhouse gases from the management of municipal waste are projected to decline from around 55 million tons $\mathrm{CO}_{2}-$ equivalents per year 1980 to 10 million tons $\mathrm{CO}_{2}$-equivalents by 2020 . In the development of recycling, together with waste being increasingly used as a material resource, we can achieve the long-term goal of becoming a recycling society. Improved recycling and limited waste volumes will give such benefits as reduced costs of waste management and reduced air pollution concerning particulate matter, nitrogen oxides loads and greenhouse gas emissions [21]. 


\subsection{Assessment of energy and traffic}

LCA emissions of acidifying substances for various energy systems were calculated in 2000. The LCA study shows the future energy production trends with the lower $\mathrm{SO}_{2}$ loads in electricity production. The EEA results from this study $[22,23]$ are in Fig. 3. The highest amounts of $\mathrm{SO}_{2}$ exist with coal. Some what higher values exist with geothermal, biogas and wood based energy production although, compared to average, the values are low. The report in energy assessed the key drivers, environmental pressures and some impacts from the production and consumption of energy. It also took into account the main objectives of the European policy on energy and the environment including subjects like the security of supply, competitiveness, increased energy efficiency, renewable energy and environmental sustainability. The report addressed present trends existing within EU energy production compared to other countries [22].

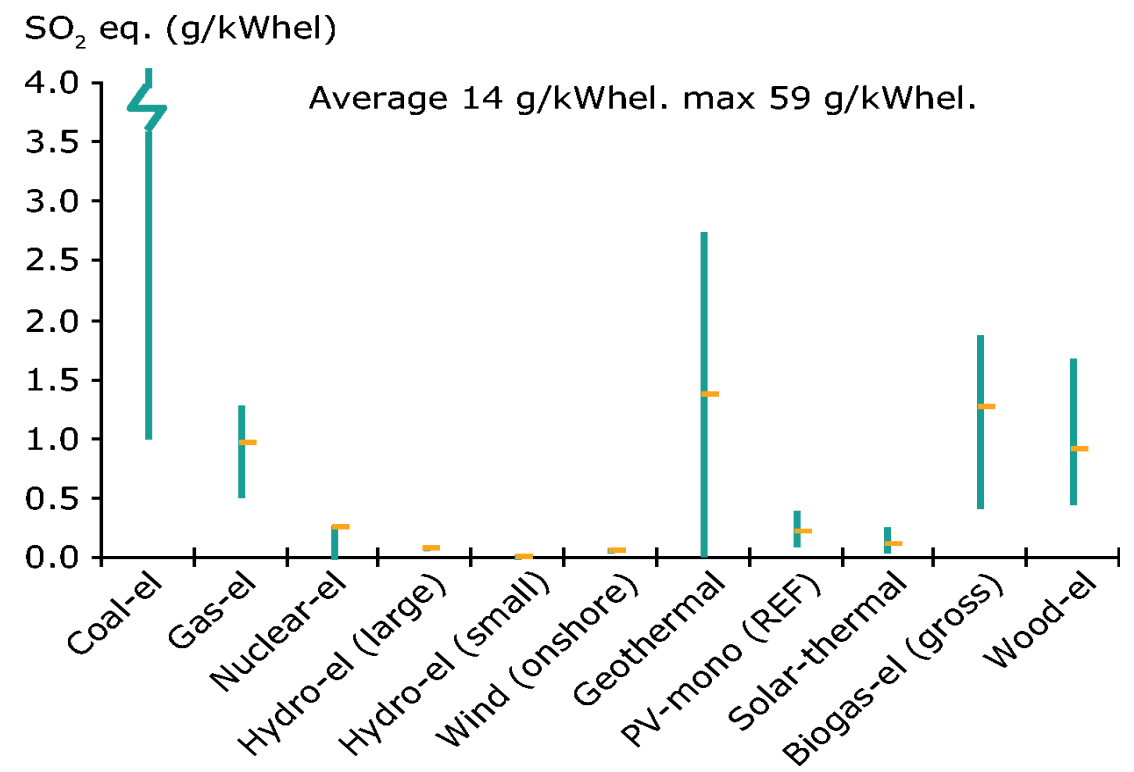

Figure 3: LCA emissions of acidifying substances for various energy systems, EEA [23].

Between 1990 and 2005, energy-related emissions of acidifying substances, tropospheric ozone precursors and particulate matter in the EU-27 countries decreased by $45-59 \%$ mainly due to improved technologies in power plants and the use of catalytic converters in road transportation. These improvements to slow down the air pollutants can also be otherwise if coal is again used more in energy production. Renewable energy and fuel technologies usually have less environmental impacts than fossil fuels. The advanced usage of bio-fuels-diesel and electric vehicles could have less impacts on the environment in cities. Particular types of bio-fuels are also more sustainable compared to non- 
renewable fossil fuels. The question is now; how rapidly the renewable technologies will be implemented and how the EU actions, proposed for energy and fuel (traffic) goals, are achieved. The production question of energy and fuels is global and concerns together with the EU-27 member states also many countries outside of Europe [22].

\section{Conclusions and remarks for the future}

On European inventory surveys (EEA annual average values), certain remarks in urban environmental impacts, exposure questions and life-cycle issues, showed good development in the potential decrease of impacts. A lot of research work, e.g. in ozone and particulate matter problems must be made. In the future, this will focus on updating the needs and tools for improving the wellbeing of the population in large cities, towns and urban areas. Nitrogen Dioxide pollutes air mainly as a result of road traffic and energy production. Heat island effect can be a problem in metropolitan areas. Hot and poor wind of polluted air (trapping of dust), especially PM2.5 and PM10 suspended particles with hydrocarbons can cause health problems.

Ozone in the ground-level troposphere is very harmful when staying over the city for too long periods during the hot summers. The EU's Clean Air for Europe (CAFE) Program in 2001 estimated that mobile sources in EU-15 countries in 2000, on average, generated 34\% from particulate matter PM2.5. To mobile sources of PM2.5 belong diesel passenger cars and diesel heavy duty vehicles' exhaust. The reference also gives an estimate for mortality of ozone (number of premature deaths) for emissions which, with a certain regional calculation system, in EU-15 in 1997-2003, on average, caused mortality of 18279 deaths. This is a very high approximated value, and for that reason all efforts must to be made to avoid ozone problems in the EU (Amann et al. [24]).

Heavy metals like $\mathrm{Pb}, \mathrm{Cd}$ and $\mathrm{Hg}$ have been reduced in urban air. To explain the variations, more measurements are still needed. Chlorofluorohydrocarbons (CFCs; Freons) cause still climate change risks. These chemicals, e.g. are required to be substituted based on the new European REACH chemicals regulation. The situation is the same with benzene which must be further avoided and totally forbidden [25]. Amounts of VOCs must be lowered. Maintenance, repair, traffic and industrial operations, which generate particulate impurities and dust must be controlled, based on health problems, in urban areas. From the LCA point of view, it is very important to obtain a balance for the future recycling society, e.g. between reuse of wastes as a material and waste incineration. It concerns also the balance in technology to produce renewable energy and fuels for cities. The question is, how rapidly the renewable technologies, proposed for energy and traffic goals, are implemented, and how soon the recent EU policy improvement actions are achieved. 


\section{References}

[1] The European Environment Agency (EEA), Themes Urban Environment: Indicators http://www.eea.europa.eu/themes/urban.

[2] Urban sprawl in Europe - The ignored challenge EEA Report No 10/2006 The European Environment Agency (EEA) http://www.eea.europa.eu /publications/eea_report_2006_10

[3] Tyler Miller, G., Living in the Environment Principles, Connections, and Solutions, 12th edition, Brooks/Cole/CA, fig. 26-7, fig.26-10 2002

[4] Air and health - local authorities, health and environment - EEA, Brochure No 1/1999, http://www.eea.europa.eu/publications/2599XXX

[5] NEC Directive status report 2008. Reporting by the Member States under Directive 2001/81/EC of the European Parliament and of the Council of 23 October 2001 on national emission ceilings for certain atmospheric pollutants. EEA Technical report, N. 11/2009. ISSN 1725-2237, Copenhagen, 2009. $51 \mathrm{p}$.

[6] Pulford, I. and Flowers, H., Environmental chemistry at a glance, Blackwell Publishing Ltd, Oxford UK, 55-58, 89-128, 2006

[7] Haughton, G. and Hunter, C., Sustainable cities, Cromwell Press Ltd, Melksham Great Britain, 125 -164, 165-197, 1994

[8] Assessment of ground-level ozone in EEA member countries, with a focus on long-term trends Technical report No 7/2009

[9] Good and bad ozone EEA 2006 http://www.eea.europa.eu/maps /ozone/ozone/good-and-bad-ozone

[10] Emission trends of acidifying pollutants (EU-27 - EU-15), EEA 2009, http:/www.eea.europa.eu/data-and-maps/figures/emission-trends-ofacidifying-pollutants-eu-27-eu-15

[11] Jain, R.K., Urban, L.V. and Stacey, G.S., Environmental impacts analyses A new dimension in decision making, second edition, Van Nostrand Reinhold Environmental Engineering Series, Van Nostrand Reinhold Company, New York USA, pp. 188 - 192 and Appendix B, pp. 176-324, 1981

[12] Distance to target for benzene at urban and traffic stations, EEA 2004 http://www.eea.europa.eu/data-and-maps/figures/distance-to-target-forbenzene-at-urban-and-traffic-stations-2004

[13] Aksoy, M. Hematotoxicity and carcinogenity of bentzene, Environmental Health Perspectives, Vol.82, pp. 193-197, 1989.

[14] Control of toxic substances in the atmosphere: benzene, prepared by the OECD Environment Committee and Directorate, Organisation for Economic Co-operation and Development, Pol-Poll/141,105p.,1986.

[15] Van Houdt, J.J., Mutagenic activity of airborne particulate matter in indoor and outdoor environment. Atmospheric Environment 24B, 2, pp. 207-220, 1990.

[16] Traffic related toxics (2004): Distance to target for lead and carbon monoxide at urban and traffic stations Maps and graphs-air pollution-EEA. 
[17] Distance to target (2004) for arsenic, cadmium and nickel at urban and rural stations http://www.eea.europa.eu/data-and-maps/figures/distance-to-target2004-for-arsenic-cadmium-and-nickel-at-urban-and-rural-stations

[18] Air quality Indicator 3: Exceeding of air quality standards EEA http://www.eea.europa.eu/publications/ENVISSUENo12/page008.html

[19] Limit value proposals for city pollutants: Proposed daughter Directive agreed in Council (OJ, C360/99, 23/11/98) (some of limit values have been amended in the recently adopted daughter Directive 1999/30/EC, indicated in brackets), Commission Proposal COM (98) 591 and Commission Proposal COM (99) 125

[20] EEA average particulate matter PM10 inter-annual variations 1997-2004 at selected urban background stations in different European cities. http://glossary.eea.europa.eu/terminology/sitesearch?term=PM10+INTERANNUALVARIATIONS+URBAN+STATIONS+1997

[21] Better management of municipal waste will reduce greenhouse gas emissions, EEA Briefing No 1/2008, http://www.eea.europa.eu/publications /briefing_2008_1/

[22] Energy and environment report 2008, EEA Report No 6/2008, http://www.eea.europa.eu/publications/eea_report_2008_6

[23] LCA emissions of acidifying substances for various energy systems EEA (2000), http://www.eea.europa.eu/data-and-maps/figures/lca-emissions-ofacidifying-substances-for-various-energy-systems-2000

[24] Amann, M., Bertok, I., et al., Baseline scenarios for the clean air for Europe (CAFE) programme. Final report Nr. 1, European Commission Directorate General for Environment, Directorate C - Environment and health, corrected version, February, 2005.

[25] Regulation (EC) No 1907/2006 of the European Parliament and of the Council of 18 December 2006 concerning the Registration, Evaluation, Authorization and Restriction of Chemicals (REACH). 